\title{
A MÁQUINA BINÁRIA DO ESTADO: DO DESEJO DA POLÍTICA À POLÍTICA DO DESEJO
}

\section{LA MÁQUINA BINÁRIA DEL ESTADO: DEL DESEO DE LA POLÍTICA A LA POLÍTICA DEL DESEO}

\begin{abstract}
Alan Isaac Mendes Caballero ${ }^{1}$
Resumo: Partindo de Gilles Deleuz e Felix Guattari, o Estado pode ser tomado como uma máquina binária, operando pela segmentarização de um povo transforma-o em população governável a partir da codificação e sobrecodificação do desejo por políticas sexuais. Em um contexto de neoliberalismo presenciamos propriedades heteronormativas e colonizadoras por parte dessas políticas de Estado para a regulação das máquinas desejantes, o que contribui para a permanência de desigualdades sociais. Para agir em sentido contrário, é preciso compor uma máquina de guerra a partir de práticas contrassexuais (PRECIADO, 2017) para deslocar toda a repressão-recalcamento em outros fluxos de devir.
\end{abstract}

Palavras-chave: Máquina Binária/de Guerra; políticas sexuais; contrassexualidade.

Resumen: Partiendo de Gilles Deleuze e Felix Guattari, el Estado puede ser tomado como una máquina binária, operando por la segmentarización de un pueblo transformándolo en población governable basada en la codificación e sobrecodificación del deseo por políticas sexuales. En un contexto de neoliberalismo presenciamos propiedades heteronormativas y colonizadoras de parte de esas políticas de Estado para la regulación de las máquinas deseantes, lo que contribuye para la permanencia de desigualdades sociales. Para actuar en la dirección opuesta es necesario componer una máquina de guerra partiendo de prácticas contrasexuales (PRECIADO, 2017) para desplazar toda represión-recalcamiento en otros flujos de devenir.

Palabras clave: Máquinas Binárias/de Guerra; políticas sexuales; contrasexualidad.

\section{Introdução}

Presenciamos uma sociedade de controle (DELEUZE, 2013) na qual o Estado age como uma máquina binária na produção de corpos, gêneros e sexualidades desejáveis, capturando suas subjetividades, assujeitando-os e excluindo-os das esferas públicas de convivência e dos serviços oferecidos pelo Estado, podendo-se considerar a abjeção de corpos um elemento necessário neste circuito produtivo (ROLNIK, 2018). Em contraste com as sociedades disciplinares, a governamentalidade nos séculos XX-XXI encontra na revolução tecnológica instrumentos informacionais e comunicacionais para a dispersão de signos, orientando emoções, pensamentos e desejos de um povo (ARGEMÍ et al., 2008), constatado pelas relações entre os discursos contidos no texto da política e seus efeitos midiáticos e de enquadramento, consistindo, respectivamente, em alcançar objetivos políticos predeterminados e em cuidados paliativos.

As políticas sexuais dispõem de signos a serviço da máquina do Estado, tais quais: "Direitos Humanos", "cidadania", "diversidade sexual", "igualdade de gênero" e "combate à discriminação e preconceito" e assim por diante. Em suma, os sentidos dos signos são disputados em um Estado de Bem-Estar Social com contornos neoliberais, responsável por aprofundar as desigualdades sociais que um Estado-providência pretende amenizar. Assim,

\footnotetext{
${ }^{1}$ Universidade Estadual de Campinas (UNICAMP).E-mail: alanisaac09@gmail.com.
} 
contra uma governamentalidade instituída em uma democracia burguesa são necessárias políticas de gênero para desidentificar-se da sexopolítica (PRECIADO, 2011).

Partindo desse contexto, apropriamo-nos do pensamento político-filosófico de Gilles Deleuze e Félix Guattari associado a contribuições dos estudos de gênero, sobretudo o conceito de contrassexualidade de Paul Beatriz Preciado, para aproximar o Estado e seus sujeitos com as noções de máquina binária e máquina de guerra, destacando os dispositivos de controle e suas tecnologias sexuais para a elaboração de identidades capturadas por condutas burguesas do corpo.

\section{A máquina binária do Estado}

Se o Estado opera como uma máquina binária, é sua função organizar todos os fluxos na produção de séries finitas e identificáveis, a começar por pares de opostos hierarquizáveis: as dicotomias (DELEUZE; PARNET, 2004). Quando os pares de opostos são insuficientes para promover a hierarquia, remetendo a dualismos transgressores, faz-se necessário a criação de um terceiro elemento, outro significante para limitar os sentidos dos demais, fazendo com que as linhas infinitas e imprecisas dos primeiros termos produzam a seriação desejada pela instalação de um ponto de referência capaz de capturar sentidos, concentrá-los em determinados dispositivos e dispersá-los conforme seus interesses, bem como aprisionar forças ou encurralá-las. Realizam-se estas operações consecutivamente na tentativa de obter determinada seriação de sentido, já que os canais comunicacionais encontram ruídos ou pontas soltas reparáveis com um trabalho de redundância da informação ou repetição dos atos para uma estilização das condutas (BUTLER, 2018).

A máquina binária corta, torce, estica e comprime as linhas de força que passam por ela na tentativa de produzir máquinas acopláveis ao seu sistema, capazes de realizar operações de corte, torção, estico ou compressão como extensão da primeira máquina (definida arbitrariamente pelo observador) ou por controle remoto, permitindo a primeira máquina operar à distância, porém, dentro de seus domínios, uma vez que ela e as linhas de força cooptadas para seus propósitos dividem um território comum, chegando a funcionar como uma única máquina. Consequentemente, uma máquina é um conjunto de máquinas que são um conjunto de máquinas e assim sucessivamente (DELEUZE; GUATTARI, 2010).

É recomendado, no entanto, não tomar as máquinas por suas séries, mas por seus sistemas, tornando as séries operáveis e consistentes a um só tempo (maquináveis), sendo sua produção semiótica dada pelo conjunto das partes. Importa menos a soma do que a qualidade das interações internas, pois a máquina promove um sistema de acumulação que é também um sistema de abjeção (ROLNIK, 2018). A expropriação, a integração, a desfiguração e a modificação de termos funcionam melhor do que a inclusão de um termo qualquer, pois um vetor-infecção é contingente se não são tomadas as devidas medidas profiláticas. Consequentemente, as máquinas binárias recorrem a suas operações básicas de deformação para efeitos de programação, higiene e lubrificação das peças.

Obedecendo tal linguagem cibernética são realizadas perguntas para suas respostas e não o contrário, indicação de "ideias justas" ou "palavras de ordem" (DELEUZE; PARNET, 2004). Uma dívida dada ao nascer que se estende à eternidade para ser cobrada em momentos de conveniência ou crise por operações de repressão-recalcamento. A linguagem a ser obedecida é a dos segmentos duros: "pacotes de linhas segmentarizadas" passando através de nossos limiares (DELEUZE; PARNET, p. 147, 2004), emitidos pelas máquinas binárias em suas operações de codificação e sobrecodificação, se acrescentadas as máquinas abstratas. 
A sobrecodificação é precisamente a operação que constitui a essência do Estado, que mede ao mesmo tempo sua continuidade e sua ruptura com as antigas formações: o horror dos fluxos de desejo que não seriam codificados, mas também a instauração de uma nova inscrição que sobrecodifica e que faz do desejo a coisa do soberano, ainda que como instinto de morte (DELEUZE; GUATTARI, 2010, p. 265).

Portanto, a binaridade do Estado reside na sobrecodificação do desejo para sua rentabilidade, um "sistema de subordinação-disjunção" (DELEUZE; GUATTARI, 2010, p. 348). As subjetividades, governadas por dívidas simbólicas, são arrebatadas nisso que convém chamar processo de subjetivação. Agenciam-se máquinas desejantes a máquinas territoriais por processos de sobrecodificação. Ao Estado cabe a função de integrar a dispersão energética dos fluxos de desejo descodificados. Quando a sobrecodificação não é suficiente inventa códigos para subordinar as relações concretas a sua abstração, por isso "o Estado é desejo que passa da cabeça do déspota ao coração dos súditos, e da lei intelectual a todo o sistema físico que dela se desprende ou se liberta" (DELEUZE; GUATARRI, 2010, p. 294).

Assim, o Estado oferece um paradoxo: a formação de um sistema físico e de um sistema metafísico. O corte, o recorte e a sobrecodificação são as operações físicas sobre um material, o desejo desterritorializado; para reterritorializá-lo em um circuito de equalização dos movimentos busca-se a sincronização dos processos de significação e, se possível, das práticas significantes de tal forma que as pulsões das máquinas desejantes encontrem o fluxo da máquina binária. Para isto, "o Estado, sua polícia e seu exército formam um gigantesco empreendimento de antiprodução, mas no seio da própria produção, e condicionando-a" (DELEUZE; GUATTARI, 2010, p. 313), a máquina binária emperra e obstrui os fluxos para reorganizá-los ao seu diagrama produtivo.

O duplo eixo significação-subjetivação desenha um rosto de geometria molar, o suposto crédito-sem-contrato (DELEUZE, 1997). Desta transversalidade condensam-se as corporeidades no conjunto da matéria física denominada corpo, possibilitando o aparecimento do gênero como condição existencial. Conclui-se que "a educação do sujeito e a harmonização da forma não param de obcecar nossa cultura, de inspirar as segmentações, as planificações, as máquinas binárias que as cortam e as máquinas abstratas que as recortam" (DELEUZE; PARNET, 2004, p. 153), correspondendo educação e harmonização com o eixo significação-subjetivação.

O corpo é atravessado por corporeidades, está na passagem dos fluxos. Por isso, convém investigar os agenciamentos que estão no processo de montagem entre as linhas de forças para a formação de séries dicotomizadas que exprimem enunciados redundantes de subalternidade de uma corporeidade à cadeia produtiva de uma máquina binária que tem como resultado final um corpo a ser acoplado em outras máquinas por novos agenciamentos. Para compreender como as estratégias de uma máquina binária do Estado são materializadas (diagramadas) recorremos às políticas sexuais, as ferramentas de mediação entre o desejo burguês do Estado e sua apropriação pela população.

\section{Políticas sexuais}

A tradição liberal do século XIX começa a pensar a "questão social" com o desenvolvimento do capitalismo e o crescimento da pobreza urbana. Esse fluxo preconiza o princípio da igualdade pelo o acesso aos bens sociais e a participação na riqueza socialmente produzida como estratégia para diminuir desigualdades sociais, codificadas na forma de um Estado de Bem-Estar Social (RAMALHO JÚNIOR, 2012). Seu dever constitucional passa a ser a prestação de serviços sociais à população pela distribuição e regulação de direitos sociais, 
os quais seriam uma "espécie dos direitos fundamentais da cidadania ligados aos direitos humanos próprios da dignidade da pessoa humana" (CURY, 2012, p. 150). Em contraposição, surge um corte-fluxo de Estado neoliberal contrário a essas operações e signos com um discurso de transformação no papel do Estado moderno.

O neoliberalismo caracteriza-se por princípios (ou verdades) de liberdade individual, livre mercado e propriedade privada em reinterpretação dos princípios liberais. Em um período de globalização, o capital transnacional procura conquistar novos mercados, acoplá-los a sua máquina, tendo como eixos básicos a liberalização do mercado, desregulamentação do mercado e o Estado minimalista para garantir a liberdade do fluxo de mercadorias (RAMALHO JÚNIOR, 2012). Os planos de existência são criados tendo em vista a eliminação de barreiras protecionistas e de qualquer forma de regulação do Estado nos mercados, até mesmo o assistencialismo social, seguido da transferência desse serviço para a iniciativa privada.

Uma política feminista compreende que a criação de contextos liberais está atrelada à naturalização da vulnerabilidade (BUTLER, 2017). Os impactos provocados por essas mudanças podem ser sentidos nas possibilidades de emprego com a insistência em contratos de trabalho temporários, sobretudo para o público feminino, refletido na aproximação de bemestar das mulheres com pulsões de morte (DELEUZE; GUATTARI, 2010). Isto ocorre porque o neoliberalismo depende da feminização do trabalho, indicando precariedade, flexibilidade, incerteza, baixo reconhecimento e baixos salários para uma enorme quantidade de mulheres no mercado de trabalho global (OKSALA, 2013).

Se não há incentivo ao Estado providência, interessa ao neoliberalismo de contexto global a subjetivação para o autogoverno com a produção de sujeitos adeptos à cultura empreendedora, iniciando um novo acoplamento maquínico. A vida torna-se um empreendimento em todas as suas dimensões, investindo-as de características masculinas, como a razão econômica, o autointeresse e a competitividade. No entanto, a mulher autônoma não é máquina desejante no paradigma neoliberal, sendo-lhe negada qualidades como egoísmo, possessividade e racionalidade (OKSALA, 2013).

Percebe-se que o mercado segue suas próprias leis de corte-fluxo, findando por criar cenários hostis para a aparição pública dessas mulheres-máquinas e no estabelecimento de alianças para a formação de políticas de gênero por acoplamentos indefinidos, o que "modifica a característica disruptiva e expressiva dos movimentos sociais em favor de uma relação integradora e corporativa com o Estado" (MASCARENHAS et al., 2012, p. 445) ou sobrecodificadora. Com efeito, o Estado neoliberal se recobre de neutralidade, principalmente quando suas verdades segmentarizadoras dispõem de um caráter científico para suas operações de corte-economia. Assim, o modelo de governamentalidade neoliberal assume a necessidade da extensão da racionalidade neoliberal para todas as instituições e práticas sociais, redefinindo a atuação social do Estado por atividades do Terceiro Setor, isto é, as organizações da sociedade civil.

Campanhas de combate à pobreza ou de atendimento a pessoas com HIV também estão perpassadas por um paradigma de vulnerabilidade (AMUCHÁSTEGUI, 2017). Nessas situações estão pressupostos grupos de risco, conjuntos maquínicos em condição de maior vulnerabilidade se comparados a outras máquinas. Assim, toda organização governamental do sofrimento não identifica os comportamentos de risco, mas enquadra determinados sujeitos como perigos potenciais, incorrendo até mesmo em graus de vulnerabilidade, o que permite a um imaginário social conceber uma ligação direta entre um conjunto de máquinas desejantes e um sexo, já que possuem condutas de desejo incontrolável, até promíscuos.

Sabe-se, no entanto, que esses corpos estão envolvidos em uma máquina moral produtora da vulnerabilidade enquanto enunciado de Estado, a máquina estatal divide seu poder público com máquinas privadas ao depender de ONGs feministas (especialistas em gênero) que se 
guiam por lógicas de segmentarização, chegando a interpretar a vulnerabilidade de uma mulher heterossexual casado ao vírus HIV somente em condições de passividade, impotência, vergonha e outras que possam relacioná-la a uma vítima, enquanto as mulheres que não se enquadrem nesse rosto-estereótipo têm seu atendimento obstaculizado (AMUCHÁSTEGUI, 2017).

A máquina neoliberal produz experiências fragmentadas por marcas de classe, gênero, raça, geração, nacionalidade, entre outras categorias diferenciadoras. Consequentemente, a própria luta feminista vê-se desvirtualizada pelo isolamento, divisão e segmentarização provocados pela transformação das linhas de fuga em feixes. Essas experiências são perpassadas por uma temporalidade dos espaços estriados, está dotada de um "tempo vazio homogêneo" que recobre o Estado de Bem Estar-Social como uma capa (FIRTH; ROBINSON, 2016). Tem-se um agenciamento econômico-cultural capaz de impor as temporalidades necessárias e suficientes para os interesses governamentais de desterritorializar sem reterritorializar. É instaurado nesse processo as máquinas híbridas, gestada na movimentação de atores políticos (indivíduos, grupos, organizações, etc.) agindo para conectar esferas públicas e privadas pela negociação ou disputa de políticas sexuais enquanto políticas sociais para governar os corpos e desejos de um povo, modificando o papel do Estado de Bem-Estar Social.

Deste ponto de vista, o Estado pode controlar o nomadismo (LÉON, 2012), cria dispositivos de gênero e raça para feminizar o trabalho (VARGAS-MONROY; LOMBART, 2013, p. 1262): "as mulheres do chamado terceiro mundo tem sido um dos sujeitos mais interpelados [intervenidos] desde políticas e planos de governo que buscam sua inserção dentro de formas hegemônicas de economia", cujos discursos desenvolvimentistas apelam para conceitos de empoderamento, autogestão, autodesenvolvimento e empreendedorismo, configurando uma governamentalidade neoliberal capaz de uma subjetivação feminizadora e racializadora em defesa da civilização e do desenvolvimento pela manutenção de binarismos.

Quando a Outra é exotizada aparece um componente colonial para analisar o gênero em contextos neoliberais. A cultura empreendedora exibe, portanto, seu gênero e cor, em processos de culpabilização dos sujeitos como parte do processo normalizador das condutas (PERES, 2010), como se as condições existenciais estivessem desvinculadas de contextos territoriais. A culpabilização pode ser acompanhada da criminalização e da patologização de uma população, pontos de subjetivação para o controle das pulsões desejantes, assim a colonização reorganiza os devires em um feixe de inteligibilidade (ROLNIK, 2018).

Os signos discursivos regulam a produção de identidades fixadas, cuja rigidez no cumprimento das contribuições performáticas gera sofrimentos psíquicos agravados por situações de desigualdades (BUTLER, 2017). É preciso por o desejo em circulação, o que requer a circulação dos corpos por universos ainda não acessados. Quando as instituições visam a verdade para constituir seu saber, ou quando a binarizam, não operam com o fluxo, mas com a sensação de certeza. A impossibilidade de um devir-nômade permite ao Estado governar a população através de políticas públicas, um investimento biopolítico.

O Estado policial presente nos séculos XVIII-XX teria sido aquele com prerrogativa jurídica para regular as códigos de vestimenta de indivíduos e aplicar-lhes punições quando se travestissem (ROTA IRIMIA, 2015), assim poder-se-ia garantir a segurança de uma população pela manutenção da higiene ou da vigilância sobre os corpos criminosos. Ainda hoje o discurso legal formula o que é desejável e o que é condenável, dispõe de uma ordem moral a ser seguido por lei. O Estado recorre a interpretações legais para produzir condutas adequadas e uma corporalidade esperada, recorre a processos de significação-subjetivação para o governo da população.

É assim que o Estado vem a reforçar rostidades e normas de gênero vinculadas à supremacia masculina quando compreende que o crime de abuso sexual só é possível com a penetração de um órgão ou objeto fálico à vagina ou ânus, orifícios determinados pelos 
legisladores e que excluem a boca. $\mathrm{O}$ falo, nessa situação, detém a atividade e o poder, o(s) orifício(s) penetrado(s), a passividade e a submissão (PARRINI, 2013). A violência parte de um "membro viril", não de um corpo, motivo que justifica a dessexualização da linguagem jurídica, pois ela reduz a importância da diferença sexual percebida no ato de violência ou pressupõe a igualdade de gênero sem a necessidade de interrogar acerca das territorialidades e agenciamentos disponíveis a cada sujeito. Desta forma, a interpretação jurídica incorre em uma redução dos efeitos produzidos e da dimensão do lugar do acontecimento, sem estender a uma compreensão sociológica dos fatos, pois a máquina binária resiste a sua própria sobrecodificação, ela que detém a soberania dos cortes-fluxos.

Pode-se apelar também para o "empoderamento" da mulher sem transformar as relações de poder sustentadas na diferença sexual, como quando as políticas de diversidade sexual na educação afirmam a conquista da "equidade de gênero" apenas com a evidência de maior escolarização e desempenho de meninas nas escolas, o que reduz a categoria "gênero" a "mulheres" (CARRERA, 2016). A pedagogia de resultados do neoliberalismo não contribui para explicar quadros generalizados de violência contra a mulher e obstáculos sociais para a materialização de direitos fundamentais, além de não responder adequadamente ao processo de expulsão de crianças nãoheterossexuais nas escolas, confundido com evasão escolar, provocado pela violência cotidiana nesses espaços públicos (BENTO, 2008). As políticas neoliberais já possuem verdades e os signos necessários para a difusão de seu desejo, ignorando questionamentos investigativos. Em todo caso, não se furtará a negociar a dívida carregada por seus signos.

Quando a cidadania é o eixo central da educação percebe-se o quão necessário é orientar sexualmente uma população pela produção de gêneros governáveis nas escolas e não mais por uma punição jurídica. Um currículo de gênero pode servir a uma governamentalidade democrática (GALLO, 2017), sendo os discursos de inclusão por ela veiculados uma oferta de igualdade de oportunidades em um mundo globalizado e comprometidas com a aprendizagem de habilidades e competências, conteúdos que privilegiam a formação do trabalhador ao cidadão, comunicada por meio de noções como família, reprodução, trabalho, estilo de vida e assim por diante, procurando produzir uma nacionalidade e, por isso, incitando a formação de gêneros (VIANNA; UNBEHAUM, 2016).

Esse processo de captura política das sexualidades de uma população pelo poder do Estado está situado em uma democracia burguesa. Sob estas condições, o Estado e seus atores passam a vincular políticas assistenciais, de saúde e de diversidade sexual com as concepções burguesas de prazer, família e desejo (FOUCAULT, 2015), em contraste com as experiências de vida dos usuários desses serviços, incorrendo em reducionismos da noção de vida. Isto ocorre porque a burguesia é uma "classe com vocação universalista" na axiomática capitalista, ou ainda, "classe descodificante e descodificada", "ela basta para preencher o campo da imanência do capitalismo" (DELEUZE; GUATTARI, 2010, p. 336-337). É assim que ela exibe nos Estados modernos sua função reguladora dos corpos: impõe a civilização pelo corte e reorganização dos fluxos a partir de um axioma de consumo que se instala por operações de repressão-recalcamento de signos para maquinar o desejo.

São criadas complicações na análise dessa materialidade semiótica quando a máquina binária do Estado está inserida em um circuito político-econômico de dependência no qual as políticas locais estão em comunicação com políticas globais, as quais apresentam alguma responsabilidade na promoção de objetivos burgueses através da promoção de uma agenda internacional movida pelo contexto de globalização de mercados e, portanto, conexão entre máquinas binárias, tornando-se, deste ponto de vista, máquinas híbridas: sociedades de controle estabelecidas por relações de dependência que trabalham para a imposição de um inconsciente colonial-capitalístico (ROLNIK, 2018). 


\section{A máquina de guerra ou a máquina contrassexual}

Nesse contexto é fundamental considerar as máquinas de guerra, um conjunto de forças agenciadas contra a máquina binária do Estado. Os interesses deste contramovimento ou nomadismo consiste em uma resistência na defesa dos próprios interesses, um movimento alinhado com o desejo ativo de seus sujeitos, uma luta contra a dominação, cujo desafio está em afirmar o local contra o global e, por esta razão, procura desprender-se das máquinas binárias, de suas ligações ou aparelhos de captura. A contrassexualidade (PRECIADO, 2017) é a política de movimento em oposição às políticas sexuais, uma vez que ela reconhece o sexo como ficção e não se permite ser governada por normas de gênero.

Conforme Deleuze (1997), três axiomas constituem uma máquina de guerra: no primeiro, a máquina de guerra é exterior ao Estado e por isso se contrapõe a ele, nela reside a potência guerreira que se desprende das linhas de segmentarização por uso dos afetos na condição de armas contra o Estado jurídico, mas não lhe pertence originalmente, é uma força nômade em constante metamorfose, as quais "animam uma indisciplina fundamental do guerreiro, um questionamento da hierarquia, uma chantagem perpétua de abandono e traição, um sentido da honra muito suscetível, e que contraria, ainda uma vez, a formação do Estado" (DELEUZE, 1997, p. 16).

Em seu segundo axioma, por ser uma invenção nômade, a máquina de guerra possui três aspectos: a) o aspecto espacial geográfico confere ao nômade um vetor-desterritorialização, uma viagem em um espaço aberto, com pontos indeterminados e de distribuição indefinida, nela o nômade se orienta pelo fluxo, não vai de um ponto a outro, cavalga e, por isso, não há movimento, apenas velocidade; b) o aspecto aritmético ou algébrico aparece quando é preciso organizar ou distribuir números em um espaço livre, sendo o número puro deslocamento, dotado de ritmo e articulação; c) o aspecto afetivo remete ao afeto enquanto projétil, arma que inventa a velocidade nômade e seus signos.

Finalmente, em seu último axioma, a guerra não é objeto da máquina de guerra, uma vez que fazem crescer as paisagens sem despovoá-las, fazendo do povoamento seu objeto. "Se a guerra decorre necessariamente da máquina de guerra, é porque esta se choca contra os Estados e as cidades, bem como contra as forças (de estriagem) que se opõem ao objeto positivo; por conseguinte, a máquina de guerra tem por inimigo o Estado, a cidade, o fenômeno estatal e urbano e assume como objetivo aniquilá-los" (DELEUZE, 1997, p. 88). Portanto, a guerra pressupõe a seguinte relação: máquina de guerra-aparelho de Estado.

A máquina de guerra instaura o devir-povo contra a população binarizada, implica uma multiplicidade desejante, "necessita-se ao mesmo tempo de criação e povo" (DELEUZE, 2013, p. 218). Partindo daí, a contrassexualidade (PRECIADO, 2017) se oferece como essa máquina de guerra em oposição aos "fluxos de sexualização" do Estado (LÉON, 2012), elas são uma contradisciplina sexual, a semelhança da indisciplina guerreira dos nômades. Seu conjunto de práticas opera por contratos contrassexuais, ou seja, não exigem subserviência ao Estado, os acordos são estabelecidos entre os sujeitos de forma independente da máquina binária, eles reforçam o poder de desvio.

A contrassexualidade também cria espaços no corpo e exercita sua agência com outras máquinas ou artefatos antes proibidos ou interditados. Ao opor-se às normas sexuais do Estado, o corpo desafia o espaço público e suas políticas sexuais com seu nomadismo queer, faz do gueto marginalizado uma multidão no centro do Estado (PRECIADO, 2011), orienta-se por um fluxo estranho à segmentarização, pois o desejo não se fixa em pontos, sua distribuição não é racionalizada e choca a máquina binária com arremessos de dildos, suas armas afetivas: estas coisas que variam de um objeto de plástico, um pênis, uma perna, um braço, uma cabeça, um 
corpo ou algo que possa funcionar como prótese (PRECIADO, 2017). Em outras palavras, máquinas acopladas a outras máquinas para a produção de desejo.

Pode-se assumir, para finalizar as comparações, que a sexualidade não é o objeto da contrassexualidade, mas sim a plasticidade enquanto o "fim do corpo" e a composição de um terreno vasto de possibilidades de prazer e identidades. "Sem dúvida, cada vez que um Estado se apropria da máquina de guerra [através de negociações de movimentos sociais com o Estado, instrumentalização dos interesses populares de algumas ONGs, apropriação das estratégias de políticas locais, etc.], tende a aproximar a educação do [ao] cidadão, a formação do [ao] trabalhador, o aprendizado do [ao] soldado" (DELEUZE, 1997, p. 67), mas também aproxima o gênero à norma, sexual ou não (ROTA IRIMIA, 2015). Em resposta às políticas sexuais emerge um paradigma contrassexual no qual o povo, organizado em multidão, agencia seus desejos para guerrearem contra o Estado, nessa situação o prazer não é mais um fluxo cortado, mas um fluxo cortante. A máquina de guerra passa a ser, nestas condições, máquina contrassexual que publiciza o que foi duramente confinado nos espaços privados, toda uma rede de máquinas desejantes com a coragem de desafiar as lógicas reprodutoras, colonizadoras e consumistas das políticas sexuais provindas de máquinas binárias.

Preciado (2017) sugere que o cu ou ânus é a potência revolucionária para uma política contrassexual, enquanto o dildo desdobra uma possibilidade analítica da sociedade heterossexual. Pode-se dizer que a discussão feita aqui acerca das políticas sexuais enquanto ferramentas de uma máquina binária do Estado compõe o esforço de tal analítica. Em outras palavras, a máquina binária do Estado produz corpos sexuados pelo uso de dildos, ainda que não reconheça estas próteses enquanto tal, resultado de uma racionalidade heteronormativa. As multidões queer (PRECIADO, 2011) oferecem, neste cenário, como máquinas contrassexuais diante da sexopolítica das máquinas binárias.

\section{Conclusão}

Considera-se que a exploração dos conceitos de máquina binária (ou máquina híbrida) e máquina de guerra contribuem para situar os sujeitos na relação desejo-política de uma era de fragmentação das relações humanas e da própria noção democrática do que é uma vida humana quando esses novos modos de existência são levadas a cabo pelos discursos e signos da máquina binária do Estado; contribui também para compreender o quanto as dimensões do poder do Estado não estão limitadas ao seu próprio sistema nacional, mas também às tecnologias que transformam sujeitos em máquinas acopladas à máquina do Estado, agenciando a política do desejo ao desejo da política. A partir desta exposição, Gilles Deleuze e Felix Guattari orientam um pensamento político na valorização do povo como manifestação da vida e inspira uma política das multiplicidades corpóreas pelo desejo revolucionário, destacando-se a necessidade de levar em consideração as resistências, agenciamentos entre sujeitos e o devir para a elaboração de políticas de identidade que valorizem as diferenças, é neste sentido que a contrassexualidade de Paul Beatriz Preciado se oferece como pulsão de uma máquina desejante em combate ao inconsciente colonial-capitalístico (ROLNIK, 2018), o qual é produzido em conjunto com a heternormatividade.

\section{Referências}

AMUCHÁSTEGUI, Ana. Gobernanza neoliberal en la epidemia del VIH/SIDA en mujeres en México: los efectos del paradigma de la vulnerabilidad. Estudios Sociológicos, México, v. 35, n. 104, p. 343-371, 2017. 
ARGEMÍ, Miguel Domènech; BALESTRIN, Viviane Giusti; STREY; Marlene Neves. A emoção é o consumo: subjetivação e agenciamento da vida capital. Athenea Digital, Colombia, n. 13 , p. $121-132,2008$.

BENTO, Berenice. O que é transexualidade? São Paulo: Brasiliense, 2008.

BUTLER, Judith. Vulnerabilidad corporal, coalición y la política de la calle. Nómadas, n. 46, abr. 2017.

BUTLER, Judith. Os atos performativos e a constituição do gênero: um ensaio sobre fenomenologia e teoria feminista. Cadernos de leituras, n. 78, jul. 2018.

CARRERA, Denise. O informe Brasil - gênero e educação da CONAE às diretrizes nacionais. In: CARRERA, Denise et al. (Org.). Gênero e educação: fortalecendo uma agenda para as políticas educacionais. São Paulo: Ação Educativa, Cladem, Ecos, Geledés, Fundação Carlos Chagas, 2016, p. 25-54.

CURY, Carlos Roberto Jamil. Educação como direito social. In: CASTRO, Carmem Lúcia Freitas et al. (Org.). Dicionário de políticas públicas. Barbacena: EdUEMG, 2012, p. 148-51.

DELEUZE, Gilles. Crítica e clínica. Trad. Peter Pál Pelbart. São Paulo: Editora 34, 1997.

DELEUZE, Gilles. Conversações, 1972-1990. Trad. Peter Pál Pelbart. 3. ed. Rio de Janeiro: Editora 34, 2013.

DELEUZE, Gilles; GUATTARI, Felix. $O$ anti-Édipo: capitalismo e esquizofrenia. Trad. Luiz Orlandi. São Paulo: Editora 34, 2010.

DELEUZE, Gilles; PARNET, Claire. Diálogos. Lisboa: Relógio D'Água, 2004.

FIRTH, Rhiannon; ROBINSO, Andrew. For a revival of feminist concousness-raising: horizontal transformation of epistemologies and transgression of neoliberal TimeSpace. Gender and Education, v. 28, n. 3, p. 343-358, 2016.

FOUCAULT. Michel. História da sexualidade 1: a vontade de saber. Trad. Maria Thereza da Costa Albuquerque e José Augusto Guilhon de Albuquerque. 2. ed. São Paulo: Paz e Terra, 2015.

GALLO, Silvio. Biopolítica e subjetividade: resistência? Educar em Revista, Curitiba, n. 66, p. 77-94, out.-dez. 2017.

LÉON, Adriano de. Os labirintos do desejo: desenhando uma metodología anarcoqueer. Política \& Trabalho, n. 36, p. 219-235, abr. 2012.

MASCARENHAS, Leonardo Balbino; FARIAS, Geniana Guimarães; COSTA, Cláudia Ocelli. Terceiro Setor. In: CASTRO, Carmem Lúcia Freitas et al. (Org.). Dicionário de políticas públicas. Barbacena: EdUEMG, 2012. p. 454-7. 
OKSALA, Johanna. Feminism and neoliberal governmentality. Foucault studies, n. 16, p. 3253, 2013.

PARRINI, Rodrigo. Falos interdictos: cuerpos, masculinidade y lei. Nómadas, n. 38, p. 65-79, abr. 2013.

PERES, Wiliam Siqueira. Cartografias clínicas, dispositivos de gêneros, estratégia saúde da família. Estudos Feministas, Florianópolis, n. 18, v. 1, p. 205-20, jan-abr. 2010.

PRECIADO, Paul Beatriz. Multidões queer: notas para uma política dos "anormais". Estudos Feministas, Florianópolis, n. 19, v. 1, p. 11-20, jan.-abr. 2011.

PRECIADO, Paul Beatriz. Manifesto contrassexual. Trad. Maria Paula Gurgel Ribeiro. São Paulo: n-1 Edições, 2017.

RAMALHO JÚNIOR, Álvaro. Neoliberalismo (perspectiva teórico/conceitual) e Neoliberalismo empírico. In: CASTRO, Carmem Lúcia Freitas et al. (Org.). Dicionário de políticas públicas. Barbacena: EdUEMG, 2012. p. 346-57.

ROLNIK, Suely. Esferas da insurreição: notas para uma vida não cafetinada. São Paulo: N-1 Edições, 2018.

ROTA IRIMIA, Antón Fernández de. Sexo y monstruosidade: uma genealogia de la policía del sexo. Anthenea Digital, Colombia, v. 16, n. 2, p. 169-203, jul. 2015.

VARGAS-MONROY, Liliana; LOMBART, Margot Pujal I. Gubernamnetalidad, dispositivos de género, raza y trabajo: la conducción de la conducta de las mujeres trabajadoras. Universitas psychologica, v. 12, n. 4, p. 1255-67, oct-dic. 2013.

VIANNA, Cláudia; UNBEHAUM, Sandra. Contribuições da produção acadêmica sobre gênero nas políticas educacionais: elementos para repensar a agenda. In: CARRERA, Denise et al. (Org.). Gênero e educação: fortalecendo uma agenda para as políticas educacionais. São Paulo: Ação Educativa, Cladem, Ecos, Geledés, Fundação Carlos Chagas, 2016. p. 55-120. 